\title{
Care at the End of Life and Euthanasia
}

\author{
Medical Ethics Committee \\ Islamic Medical Association of North America
}

The sanctity of human life is ordained in the Qur'an (the holy book of Islam). "Do not take life which God has made sacred except in the course of justice,"' and "anyone who has killed a fellow human except in lieu of murder or mischief on earth, it would be as if he slew the whole mankind."2

About suicide, the Qur'an is very clear: "Do not kill yourselves as God has been to you very merciful." Taking away the life should be the domain of the one who gives life. True, there is pain and suffering with terminal illness, but we believe there is reward from God for those who patiently persevere in suffering. ${ }^{4.5}$

While Muslim physicians are not encouraged to artificially prolong the misery in a vegetative state, they are ordained to help alleviate suffering. The Qur'an says, "Anyone who has saved a life, it is as if he has saved the life of whole mankind." 6

There is no doubt that the financial cost of maintaining the incurably ill is a factor. However, the question is when the human machine has outlived the productive span and its maintenance becomes a financial burden on society, should it be discarded abruptly or allowed to die naturally, gradually and peacefully? Islamically, when individual means cannot cover the needed care, it becomes a collective responsibility of the society. To meet this objective, the society has to reshuffle its values and priorities and divert some funds from those spent on the treatment of alcoholism, drug abuse, teenage pregnancy, cigarettes, and other such "pursuits of happiness" to providing health care for those who are hopelessly ill and allowing them to live with quality and die in dignity.

The IMA endorses the stand that there is no place for euthanasia in medical management, under whatever name or form (e.g., mercy killing, suicide, assisted suicide, the right to die, the duty to die, etc.). Nor does it believe in the concept of a willful and free consent in this area. The mere existence of euthanasia as a legal and legitimate option is already pressure enough on the patient, who would correctly or incorrectly, read in the eyes of his/her family the silent appeal to go.

At the same time, the IMA holds the view that when the treatment becomes futile, it ceases to be mandatory. This would determine the utility of the administration or continuation of medical treatment (including the respirator). Under such conditions, however, the basic human rights of hydration, nutrition, nursing and pain relief cannot be withheld. These may be carried out at home or in an institution as the case warrants. Palliative care units or institutions would answer such need, but we are not certain whether this justifies the branching off of a full-blown medical specialty for palliative care. Adequate public debate (and education) should precede and proceed to necessary legal adjustments.

It is realized that the demarcation line between futile and infutile medical treatment is often blurred. Proximity to death cannot define futility of treatment, since near-dead patients may offen be successfully treated and revived. The gray area between futile and promising treatment should be narrowed as much as possible, and the subjective element in it should be minimized. An independent second opinion might be of help. However this area remains open to research. Perhaps the relation of outcomes to a battery of clinical parameters, or combinations thereof, might help the establishment of a "futility index" with reasonable precision, that would further guide the current clinical assessment.

The IMA follows the current DNR (do not resuscitate) policy, where treatment is deemed futile. Brain death including the brain stem, is an acceptable definition of death, with all the consequences pertaining to cessation of animation or the procurement of vital organs for transplantation.

Because the emphasis in such patients is not on treating the primary disease but on ameliorating the quality of life, research is recommended towards controlling the accompanying symptoms like pain, weakness, excretory dysfunction, ulceration, etc. Gadgets and aids can make a big 
difference.

Affective and psychological care is important, and both caregivers and family (guidelines or brief courses) should be trained for it. Perlaps music therapy should be further looked into as a significant addition to the management.

The spiritual dimension should be recruited to help the patient. This is not the function of clergy only, but health professionals should have adequate training in handling patients and guiding families. Care of the terminally ill should not belong in "rush" medicine or hurried physicians.

Caregivers should have an insight into the various religious, cultural, and ethnic backgrounds pertaining to terminal illness and death. A book may be collated indicating culture-specific guidelines.

Since we live in a time when one's home is no more suitable to be born in or to die in, reliance has become heavy on institutional care, which tremendously pushes up the cost of the care. Encouragement of volunteerism and perhaps providing incentives might cover part of this gap and is good for the moral health of society at large.

Of course, the issue of care for the terminally ill, as a component of health care in general, is closely combined with the modern trends in restructuring health care. It is regrettable to see that the business aspects of health care are expanding at the expense of the service (humane) side of health care. A radical review is needed, but we seem to be drifting away from it. It takes a society that is more human oriented than dollar oriented.

Some of the most critical topics for research include defining and identifying end-of-life issues and educating physicians and the public about these issues. The thirdparty provider also needs to understand that the sanctity of life is more comprehensive than a mere cost factor.

IMA makes the following suggestions:

1. Development of assessment tools and uniform endof-life issues guidelines by appropriate "specialists."

2. Specific and appropriate tests to arrive at the agreed-upon diagnosis and prognosis.

3. Define areas in which to improve care and sustain the quality of life not at the cost of termination of life (i.e., improved home health care).

4. Avoid developing such specialties that can easily be overused or misused, but rather educate all physicians in these issues.

5. Make advance directives a part of all hospital and office medical records of a patient.

\section{References}

1. Glorious Qur'ān, Chapter 6, Verse 151.

2. Glorious Qur'ān, Chapter 5, Verse 32.

3. Glorious Qur'ān, Chapter 4, Verse 29.

4. Glorious Qur'än, Chapter 39, Verse 10.

5. Glorious Qur'an, Chapter 31, Verse 17.

6. Glorious Qur'än, Chapter 6, Verse 32. 